\title{
Different Methods and Technical Considerations of Decompressive Craniectomy in the Treatment of Traumatic Brain Injury: A Review
}

\author{
Amit Kumar Ghosh ${ }^{1}$ \\ ${ }^{1}$ Global Heath City Chennai, Chennai, Tamil Nadu, India \\ Indian J Neurosurg 2017;6:36-40.
}

\begin{abstract}
Address for correspondence Amit Kumar Ghosh, DNB, Embassy Residency, Perumbakkam, Saraswati-Rajasekhar Salai, Chennai, Tamil Nadu 600100, India (e-mail: amitghosh74@yahoo.co.in).
\end{abstract}

\begin{abstract}
Keywords

- decompressive craniectomy

Decompressive craniectomy, which is performed worldwide for the treatment of severe traumatic brain injury (TBI), is a surgical procedure in which part of the skull is removed to allow the brain to swell without being squeezed. On 1901, Kocher was the first surgeon to promote surgical decompression in posttraumatic brain swelling. In this article, different methods of decompressive craniectomy and its technical considerations have been reviewed.
\end{abstract}

\section{Introduction}

The first decompressive craniectomy was presented by Kocher on $19011^{1,2}$ followed by Cushing in $1905^{3}$ and Horsley in $1906{ }^{2}$ However, because of unpleasant aesthetic results, the procedure lost its general acceptance. $^{2}$

In traumatic brain injury (TBI), the benefit of this procedure has been agreed as well as disagreed. In 1940, Erlich suggested decompressive craniectomy for all head injuries with persistent coma for more than 24 hours. ${ }^{2}$ Rowbotham (1942) recommended decompressive craniectomy for all patients for whom medical treatment was ineffective for first 12 hours. $^{2}$ During 1960 to 1970, Mayfield, Moody, Lewin presented papers noting high mortality with this procedure discouraging its use. ${ }^{2}$

After the introduction of computed tomographic (CT) scan on 1975, Ramshoff, Morantz presented decompressive craniectomy in series of comatose patients with traumatic acute subdural hematomas with $40 \%$ survival rate and $27 \%$ back to normal life. ${ }^{2}$ However, the method still did not get general approval.

The credit of rediscovering the benefit of decompressive craniectomy goes to Guerra et $\mathrm{al}^{4}$ in 1999 who published their 20 years results of decompressive craniectomies using CT scan and intracranial pressure (ICP) monitoring in Journal of Neurosurgery. His evidence-based good results allowed this technique to be accepted as a recommended therapy for refractory ICP. At present, the European Brain Injury Consortium and Brain Trauma Foundation guidelines for severe TBIs recommend decompressive craniectomy as a treatment for refractory intracranial hypertension that does not respond to medical therapeutic measures., ${ }^{5,6}$

Concept of decompressive craniectomy is related to the Monro-Kellie doctrine. The brain is a soft organ housed in a stiff box (the skull). Apart from the brain substance, this box also houses arterial and venous blood and cerebrospinal fluid (CSF). Any increase in any one of these components will result in a shift of any other component from the box or increased pressure within the box (ICP). Decompressive craniectomy is performed to increase the size of the box so that the extra volume can be accommodated. Thus "a lifesaving procedure."

\section{Different Methods of Decompressive Craniectomy in the Treatment of TBI}

Different methods of craniectomies have been described which include circular decompression, subtemporal craniectomy (Cushing), large fronto-temporoparietal decompressive craniectomy (standard trauma craniectomy), bifrontal craniectomy, large fronto-temporal or temporo-parietal craniectomy, and hemispheric craniectomy. ${ }^{7,8}$ received

February 7, 2016

accepted

March 11, 2016

published online

March 16, 2017
DOI http://dx.doi.org/

$10.1055 / \mathrm{s}-0036-1584585$ ISSN 2277-954X.
License terms

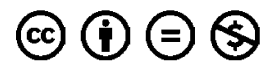
( (c) 2017 Neurological Surgeons' Society
of India 
Circular decompression was unable to take effect because of the limited space. ${ }^{9}$ Subtemporal craniectomy the was introduced by Cushing ${ }^{1,3}$ involves removing the part of the skull beneath the temporal muscle by opening the dura. ${ }^{10}$ This procedure also gives inadequate decompression effect. ${ }^{11}$ Furthermore, this procedure may lead to temporal lobe herniation and necrosis. ${ }^{11}$ At present, the more widely used methods include large unilateral frontotemporoparietal craniectomy/hemisphere craniectomy for lesions or swelling confined to one cerebral hemisphere, and bifrontal craniectomy from the floor of the anterior cranial fossa to the coronal suture to the pterion for diffuse swelling. ${ }^{7,11}$ Large decompressive craniectomies, including frontotemporoparietal/hemisphere craniectomy and bifrontal craniectomy, seemed to lead to better outcomes in patients with severe TBI compared with other varieties of surgical decompression in previous literature, ${ }^{4,8,12}$ The most direct proof was provided by Jiang et $\mathrm{al}^{8}$ : a prospective, randomized, multicenter trial suggested that large frontotemporoparietal decompressive craniectomy (standard trauma craniectomy) significantly improved the outcome in severe TBI patients with refractory intracranial hypertension, compared with routine temporoparietal craniectomy, and had a better effect in terms of decreasing ICP. ${ }^{8}$ Munch et al found that large frontotemporoparietal craniectomy could provide as much as $92.6 \mathrm{~cm}^{3}$ additional space (median: $\left.73.6 \mathrm{~cm}^{3}\right)^{7,11}$

Decompressive craniectomy is sometimes combined with a simultaneous lobectomy. ${ }^{13,14}$ However, this should be performed with caution because excessive excavation of brain tissue may lead to poor results, though the ICP could be reduced rapidly. ${ }^{13}$

\section{Technical Considerations}

\section{Scalp Incisions}

Different methods of scalp incisions ${ }^{2}$ have been described such as classic "question mark" flap ( - Fig. 1), second optional flap (-Fig. 2), and bicoronal flap(-Fig. 3). Usually, the temporalis muscle is dissected along with scalp in one plane (osteoplastic flap), by using monopolar cautery. According to another technique, the temporalis muscle may be mobilized separately, and its fascia may be dissected and harvested for the duraplasty. ${ }^{7,15,16}$ Superficial temporal artery and the branches of the facial nerve always be tried to preserve during scalp and temporalis muscle elevation. ${ }^{15,16}$

\section{Bone Removal}

The amount of bone removal in unilateral decompressive craniectomy has been described in RESCUEicp study, ${ }^{17}$ which is a wide craniectomy ( $\geq 12 \mathrm{~cm}$ in diameter) descending down to temporal fossa base and posteriorly up to asterion, and also has been described in Romanian Neurosurgery ${ }^{2}$ and some other studies. ${ }^{7,16,18,19}$

Key point of bone removal is to remove the bone up to middle cranial fossa base to decompress the temporal lobe and prevent uncal herniation, and also up to asterion posteriorly. ${ }^{16,19}$

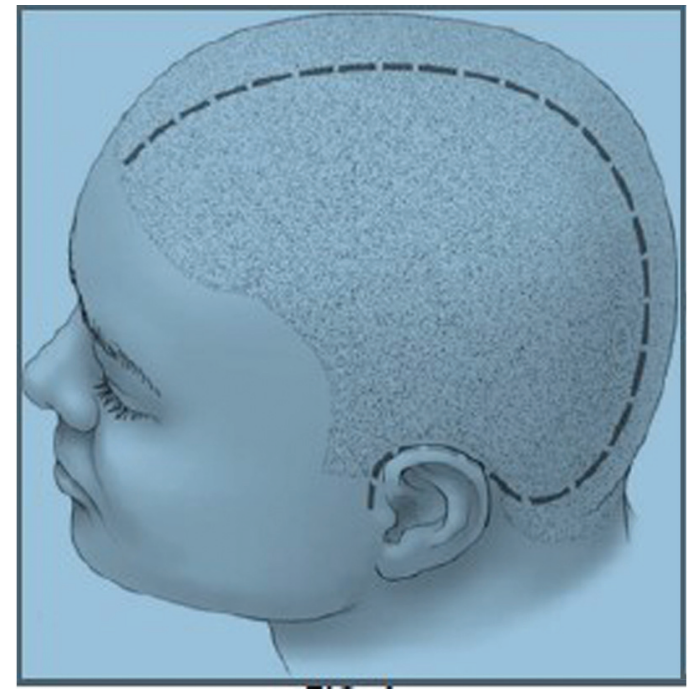

Fig. 1 Classic "question mark" trauma flap. ${ }^{2}$

Burr holes can be placed to the pterion, temporal bone, and posterior parietal and frontal regions, as close as possible to the scalp incision, taking advantage of the whole skin flap. Then, the underlying bulging dura is carefully stripped off the bone, in all the burr holes with the use of a dissector. The burr holes are connected by using a Gigli saw or high-speed craniotome., ${ }^{7,16}$

In bilateral hemicraniectomy, a bone ridge of approximately 3 to $4 \mathrm{~cm}$ in width is preserved over the superior sagittal sinus. 2,16

In bifrontal decompressive craniectomy, ${ }^{16,20}$ a bicoronal skin flap is performed and a frontotemporal bone flap including the bone over the superior saggital sinus is removed as a single piece. A key point of this procedure is the careful elevation of the bone flap, which requires careful dissection of the underlying superior saggital sinus. A variant of bifrontal craniectomy implies preserving a frontal median bone over the superior saggital sinus. ${ }^{2}$

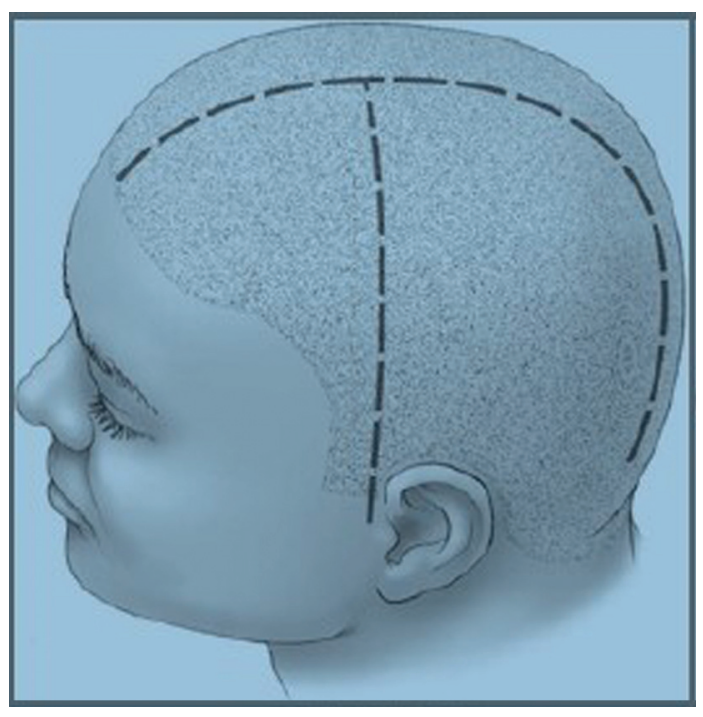

Fig. 2 Second optional flap. ${ }^{2}$ 


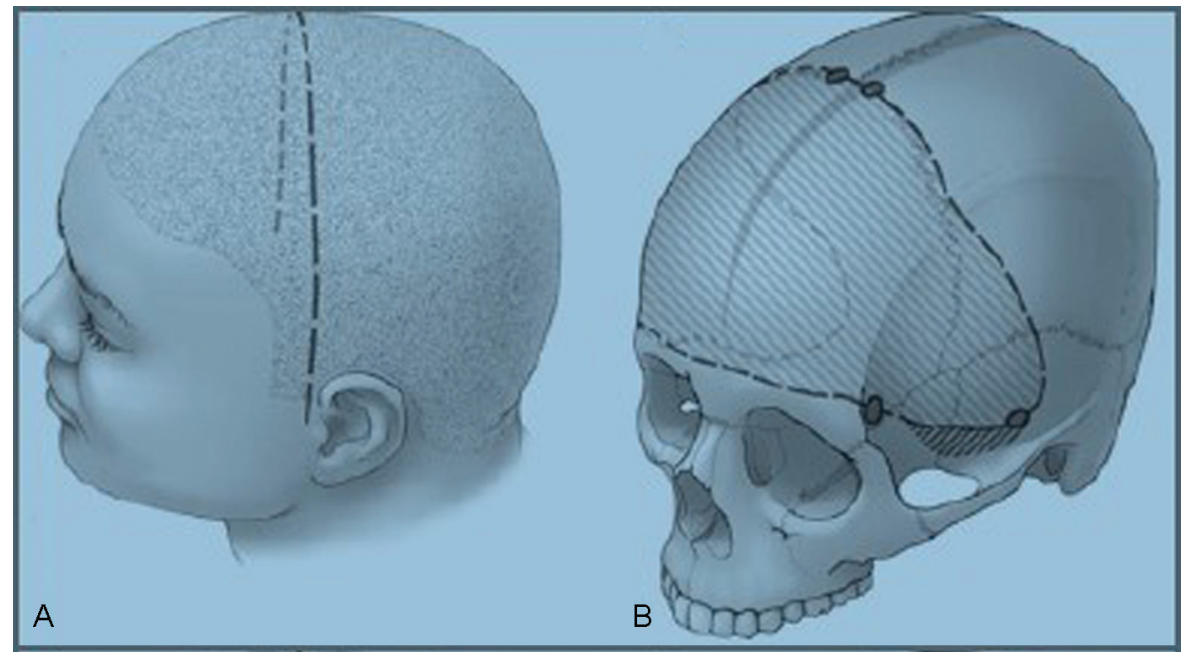

Fig. 3 Bicoronal flap. ${ }^{2}$

\section{Dural Opening and Duraplasty}

Decompressive craniectomy, dural opening, and augmentative duraplasty could maximize brain expansion and recommended by most authors. ${ }^{7,16}$

It showed better outcome and lower incidences of secondary surgical complications such as brain herniation through the craniectomy defect, epilepsy, intracranial infection, and CSF leakage through the scalp incision or contralateral intracranial lesion compared with those who only underwent surgical decompression, leaving the dura open. ${ }^{21}$ Keeping the dura open with no protection for the underlying brain tissue may increase the risk of these complications. ${ }^{21}$

The dura can be opened in a C-shaped fashion ( - Fig. 4 ) or stellate fashion (-Fig. 5) or four-flap technique (-Fig. $\mathbf{6}){ }^{2}$ The dura is enlarged with the patient's own tissue, such as temporal fascia, temporal muscle, or galea aponeurotica or with artificial material. ${ }^{7}$

Yu et $\mathrm{al}^{7,22}$ described separation of the temporal deep fascia from the temporal muscle to the zygomatic arch, and then cut the fascia from the base backward along the zygoma

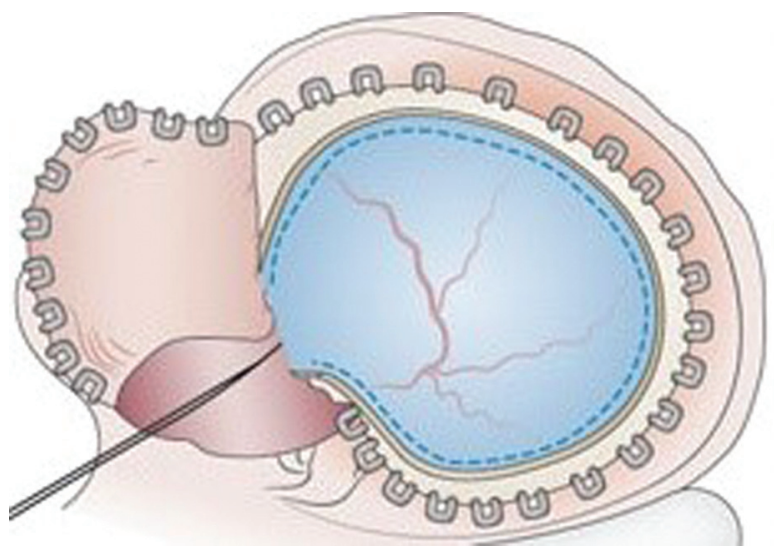

Fig. 4 C-shaped dural opening. but left the fascia base 1 to $2 \mathrm{~cm}$ long for the blood supply. Finally, they turned the temporal fascia beneath the temporal muscle and sutured it to the dura. Four-flap duraplasty has been described by Shima et al ( - Fig. 7) ${ }^{19}$

Csókay et $\mathrm{a}^{7,23}$ described "vascular tunnel" method to prevent brain herniation via the craniectomy defect that may lead to compression of vessels and result in ischemic necrosis of the portion of the herniated brain dural incisions in a stellate fashion, and then keeping hemostatic sponge supporting vessels in between the dura and brain.

Another method, lattice duraplasty, ${ }^{24}$ was also introduced by Mitchell et al to avoid herniation of the brain through the cranial defect. After conventional craniotomy, they made a series of dural incisions, each $2 \mathrm{~cm}$ long and with $1-\mathrm{cm}$ intervals. The process was repeated in parallel rows of incisions so that each incision in one row was adjacent to an intact dural bridge in the rows on either side. The same course was then performed, but in a direction vertical to the initial incision.

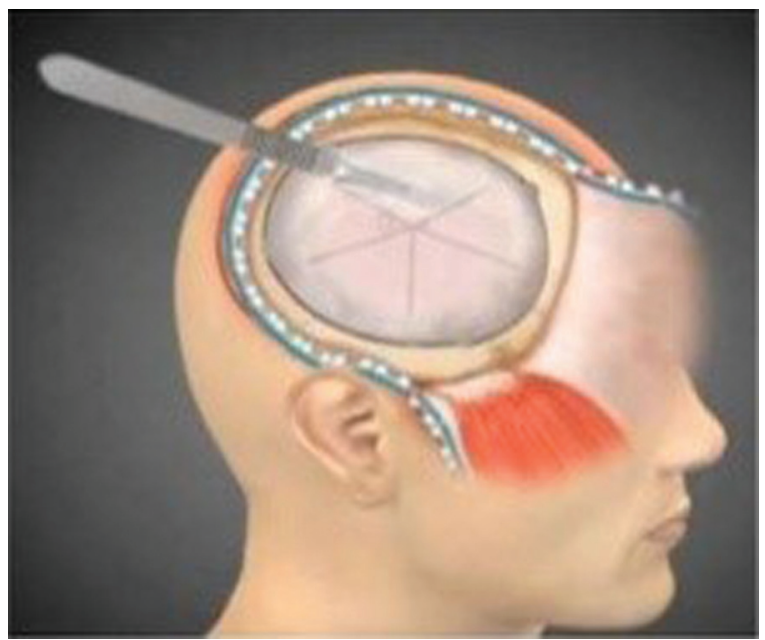

Fig. 5 Stellate. 


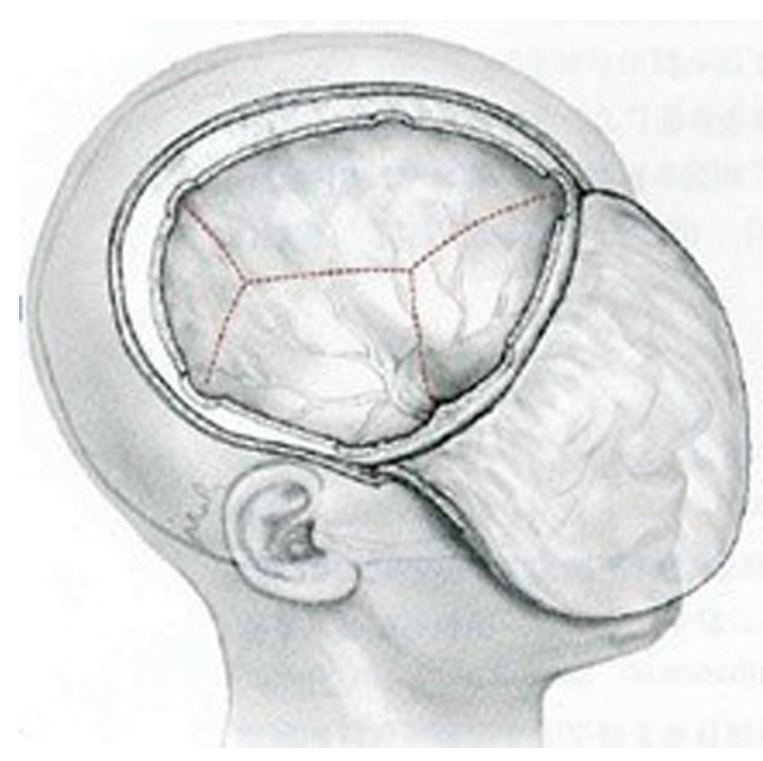

Fig. 6 Four-flap dural opening. ${ }^{19}$

\section{Some Other Technical Modifications}

The "Tucci flap" was suggested by Goettler and Tucci ${ }^{25}$ and similar technique called "in situ hinge" craniectomy was introduced by Ko and Segan." ${ }^{26}$ After decompressive craniectomy, there is theoretical risk of injury to the unprotected brain. Moreover, with the skin flap concavity, the hydrodynamic disturbance of CSF circulation and the decrease in cortical perfusion hinder patient recovery. After craniotomy, removal of the intracranial lesion, and duraplasty, the bone flap was replaced and one side of the flap was attached to the cranium by plates. The plates act as a hinge that allows the unattached portion of the bone flap to float out with bone swelling.

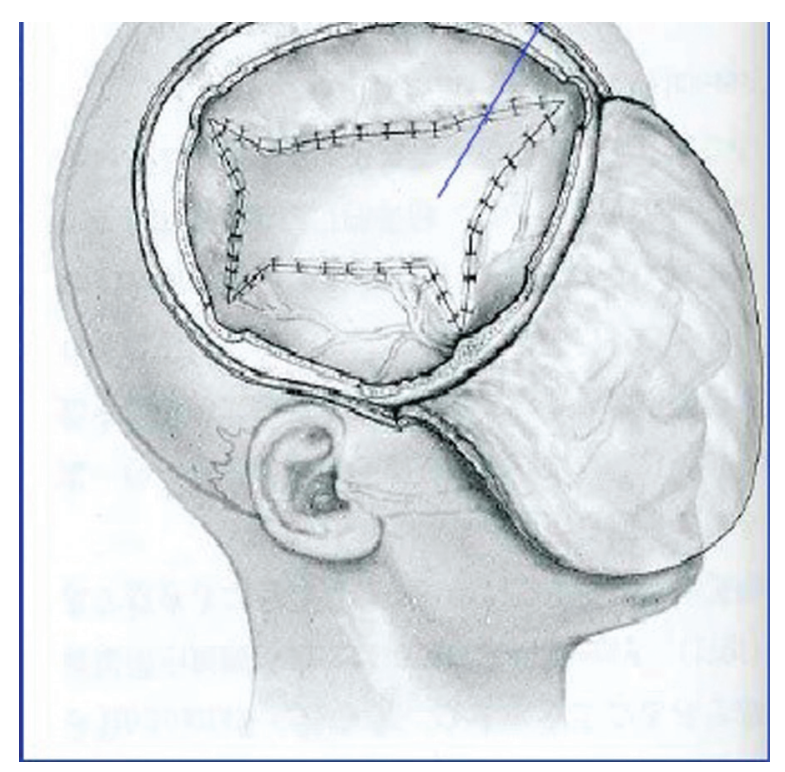

Fig. 7 Four-flap duraplasty as shown by blue line. ${ }^{19}$

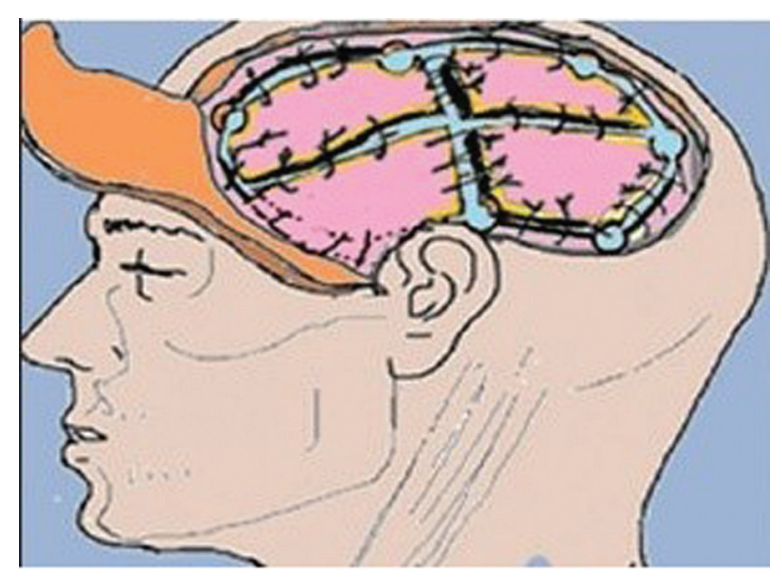

Fig. 8 Four-quadrant osteoplastic decompressive craniotomy by Peethambaran and Valsalmony. ${ }^{27}$

Peethambaran and Valsalmony ${ }^{27}$ described a technique for decompressive craniectomy (-Fig. 8) to avoid revision cranioplasty after surgery by loosely suturing four pieces of craniectomized bone with the skull.

Vakis et $\mathrm{al}^{28}$ introduced a method to prevent peridural fibrosis after decompressive craniectomy. Development of multiple adhesions among the dura, temporal muscle, and galea would be a problem during subsequent cranioplasty, and would also be a potentially deleterious factor for patient recovery. To prevent adhesions, the authors placed a dural substitute between the dural layer and galea aponeurotica after augmentative duraplasty with temporal muscle.

To increase the space of decompressive craniectomy, Zhang et $\mathrm{al}^{29}$ suggested a method of surgical decompression combined with removal of the temporal muscle part. However, survivors developed a higher rate of mastication disability.

Bhat et $\mathrm{al}^{30}$ described multidural stabs or SKIMS-technique that showed that multiple incision of the dura in acute subdural hematoma drains the hematoma, relieves ICP rapidly, and avoids brain pouting and cortical lacerations during surgery.

\section{Closure of Wound}

Dural hitch stitches have been recommended to prevent extradural hemorrhage. Subgaleal suction drain can be given with low suction. Two layered (galea and skin) is always good for subsequent healing and also to prevent CSF leak.

\section{Conclusion}

A surgeon has to standardize his/her technique of decompressive craniectomy that is the most common lifesaving neurosurgical procedure according to available literature to give the maximum therapeutic decompression effect by removing adequate bone, relieving refractory ICP, and restoring cerebral blood flow, and also following the techniques to avoid subsequent complications. 


\section{References}

1 Piek J. Decompressive surgery in the treatment of traumatic brain injury. Curr Opin Crit Care 2002;8(2):134-138

2 Balan C, Alliez B. Decompressive craniectomy from option to standard-Part I. Romanian Neurosurgery 2009;16(2):20-26

3 Cushing $\mathrm{H}$. The establishment of cerebral hernia as a decompressive measure for inaccessible cerebral tumors: with the description of intermuscular methods of making the bone defect in temporal and occipital region. Surg Gynecol Obstet 1905;1:297-314

4 Guerra WK, Gaab MR, Dietz H, Mueller JU, Piek J, Fritsch MJ. Surgical decompression for traumatic brain swelling: indications and results. J Neurosurg 1999;90(2):187-196

5 Maas AI, Dearden M, Teasdale GM, et al; European Brain Injury Consortium. EBIC-guidelines for management of severe head injury in adults. Acta Neurochir (Wien) 1997;139(4):286-294

6 The Brain Trauma Foundation. The American Association of Neurological Surgeons. The Joint Section on Neurotrauma and Critical Care. Management and prognosis of severe traumatic brain injury, part 1: guidelines for the management of severe traumatic brain injury. J Neurotrauma 2000;17:451-533

7 Huang X, Wen L. Technical considerations in decompressive craniectomy in the treatment of traumatic brain injury. Int J Med Sci 2010;7(6):385-390

8 Jiang JY, Xu W, Li WP, et al. Efficacy of standard trauma craniectomy for refractory intracranial hypertension with severe traumatic brain injury: a multicenter, prospective, randomized controlled study. J Neurotrauma 2005;22(6):623-628

9 Clark K, Nash TM, Hutchison GC. The failure of circumferential craniotomy in acute traumatic cerebral swelling. J Neurosurg 1968;29(4):367-371

10 Alexander E, Ball MR, Laster DW. Subtemporal decompression: radiological observations and current surgical experience. $\mathrm{Br}$ Neurosurg 1987;1(4):427-433

11 Kessler LA, Novelli PM, Reigel DH. Surgical treatment of benign intracranial hypertension-subtemporal decompression revisited. Surg Neurol 1998;50(1):73-76

12 Aarabi B, Hesdorffer DC, Ahn ES, Aresco C, Scalea TM, Eisenberg HM. Outcome following decompressive craniectomy for malignant swelling due to severe head injury. J Neurosurg 2006;104(4):469-479

13 Caroli M, Locatelli M, Campanella R, Balbi S, Martinelli F, Arienta C. Multiple intracranial lesions in head injury: clinical considerations, prognostic factors, management, and results in 95 patients. Surg Neurol 2001;56(2):82-88

14 Kohta M, Minami H, Tanaka K, Kuwamura K, Kondoh T, Kohmura E. Delayed onset massive oedema and deterioration in traumatic brain injury. J Clin Neurosci 2007;14(2):167-170

15 Apuzzo MLJ. Complication avoidance and management. In: Brain Surgery. Vol 2, part 4. New York, NY: Churchill Livingstone; 1993: 1283-1296

16 Gatos H, Kapsalaki EZ, Komnos A, Paterakis KN, Fountas KN. In: Agrawal A, ed. The Role of Decompressive Craniectomy in the Management of Patients Suffering Severe Closed Head Injuries, Brain
Injury-Pathogenesis, Monitoring, Recovery and Management. InTech; 2012. http://www.intechopen.com/books/braininjurypathogenesis-monitoring-recovery-and-management/therole-of-decompressive-craniectomy-in-themanagement-ofpatients-suffering-severe-closed-head-inj. Accessed March 23, 2012

17 Hutchinson PJ, Corteen E, Czosnyka M, et al. Decompressive craniectomy in traumatic brain injury: the randomized multicenter RESCUEicp study (www.RESCUEicp.com). Acta Neurochir Suppl 2006;96:17-20

18 Valadka AB, Robertson CS. Surgery of cerebral trauma and associated critical care. Neurosurgery Jul 2007;61(1): 203-220

19 Abdeen K. Decompressive craniectomy: rationale, indications and outcome. http://www.surgicalneurology.org/conf7/files/ decompressive_craniectomy.pdf. Accessed June 2015

20 Polin RS, Shaffrey ME, Bogaev CA, et al. Decompressive bifrontal craniectomy in the treatment of severe refractory posttraumatic cerebral edema. Neurosurgery Jul 1997;41(1):84-92

21 Yang XJ, Hong GL, Su SB, Yang SY. Complications induced by decompressive craniectomies after traumatic brain injury. Chin J Traumatol 2003;6(2):99-103

22 Yu HT, Wang B, Xia JG, et al. The application of turning down the deep temporal fascia to mend the dura mater in the operation of intracranial supratentorial decompression in skull trauma. Chin J Neuromed 2006;5:937-939 (In Chinese)

23 Csókay A, Együd L, Nagy L, Pataki G. Vascular tunnel creation to improve the efficacy of decompressive craniotomy in posttraumatic cerebral edema and ischemic stroke. Surg Neurol 2002;57(2):126-129

24 Mitchell P, Tseng M, Mendelow AD. Decompressive craniectomy with lattice duraplasty. Acta Neurochir (Wien) 2004;146(2): 159-160

25 Goettler CE, Tucci KA. Decreasing the morbidity of decompressive craniectomy: the Tucci flap. J Trauma 2007;62(3):777-778

26 Ko K, Segan S. In situ hinge craniectomy. Neurosurgery 2007; 60(4, Suppl 2):255-258, discussion 258-259

27 Peethambaran AK, Valsalmony J. Four-quadrant osteoplastic decompressive craniotomy: a novel technique for decompressive craniectomy avoiding revision cranioplasty after surgery. Neurol India 2012;60(6):672-674

28 Vakis A, Koutentakis D, Karabetsos D, Kalostos G. Use of polytetrafluoroethylene dural substitute as adhesion preventive material during craniectomies. Clin Neurol Neurosurg 2006; 108(8):798-802

29 Zhang MY, Zhao YF, Liang WB. The application of decompressive craniectomy combined with removal of temporal muscle in the treatment of severe traumatic brain injury. J Clin Neurosurg. 2006;3:124-125

30 Bhat AR, Kirmani AR, Wani MA. Decompressive craniectomy with multi-dural stabs-a combined (SKIMS) technique to evacuate acute subdural hematoma with underlying severe traumatic brain edema. Asian J Neurosurg 2013;8; (1):15-20 